\title{
Simultaneous changes of temperature and moisture of thermal conductivity of EPS insulation material and its impact on building energy performance
}

\author{
M. Khoukhi * \\ College of Engineering, United Arab Emirates University, Al Ain, 15551 UAE
}

\begin{abstract}
This paper investigates the simultaneous changes of combined temperature and moisture content on thermal conductivity, k-value, of polystyrene (EPS) building insulation material. In building energy analysis, the heat transfer through its envelope usually neglect the transport of moisture in the porous structure of the envelope and a constant thermal conductivity, k-value, of thermal insulation material is used to assess the heat transfer through the building envelope. In reality, the building envelope is subjected to the combined thermal and moisture gradients so that an accurate heat transfer determination requires a simultaneous calculation of both sensible and latent effects. Actually, the k-value is a complex function of temperature, moisture content, and density, which requires more accurate evaluation to lead to data that are more realistic to achieve a precise building energy assessment. The findings revealed that the impact of the change of these parameters on the cooling load calculation is significant, especially at a high operating temperature and moisture content.
\end{abstract}

Keywords: Operating temperature, Moisture content, Thermal conductivity, Building insulation material, heat and mass transfer, Building energy performance

\section{Introduction}

In Oman, due to the absence of regulation and standards, few buildings are insulated; consequently, they consume more energy than is necessary for their operation [1]. Thermal insulation is organic or inorganic material, or a combination of fibrous or particular materials, that are manufactured to slow down the rate of heat flow by a combination of modes (i.e., conduction, convection, and radiation) [2, 3].

The thermal conductivity of building insulation materials are dependent on both temperature and moisture content. In practice, in building energy assessment, constant thermal conductivity values are generally used for insulation material. The k-value is typically evaluated under standard conditions, i.e., $24{ }^{\circ} \mathrm{C}$ and $50 \pm 10 \% \mathrm{RH}[3-5]$ and single $\mathrm{k}$-value is provided by the manufacturer regardless of the temperature and moisture content. However, when placed in a building envelope under real climatic conditions, their actual thermal performance differs from that predicted under standard laboratory conditions $[6,7]$. This dependence has been reported by several investigations during the last decades. In general, the thermal conductivity k-value of building insulation materials increase with temperature and moisture content [8-13]. An extensive research dealing with the impact of operating temperature on thermal conductivity of building insulation materials under various operating temperatures has been presented by [14]. Results indicate that a higher operating temperature is always associated with higher thermal conductivity. Recently, Berardi and Naldi investigated the impact of the temperature dependent thermal conductivity of insulating materials on the effective building envelope performance. They

\footnotetext{
* Manuscript received September 10, 2018; revised January 25, 2019.

Corresponding author.E-mail address: mkhoukhi@ uaeu.ac.ae.

doi: 10.12720 /sgce.8.2.217-225
} 
conclude that for most materials, the relationship between conductivity and temperature is nearly linear. This is the case for inorganic fiber insulations (e.g. fiberglass and rock wool) and some petrochemical insulating materials (e.g. extruded polystyrene), which show lower thermal conductivity at lower temperatures. However, some materials, such as the blown foam insulations (e.g. polyisocyanurate), exhibit non-linear relationships between conductivity and temperature [15].

On the other hand, a good number studies have dealt with moisture transfer and thermal performance of insulation materials in the presence of moisture. Recent paper dealing with dynamic thermal response of building layers in aspect of their moisture content reported that the presence of the moisture on the surface of building component including the insulation material affects its energy efficiency and causes deterioration that causes change of their thermal conductivity [7]. In fact, the accumulation of moisture in building materials, leads to the increase of the building insulation material thermal conductivity, k-value, and decrease of their insulation capacity [16-21].

Dynamic Insulation Materials (DIMs) are emerging as promising new technology, which allows the rate of heat transfer through a wall to be varied over time to reduce energy consumption required to maintain thermal comfort in buildings [22, 23].

Up to now, several studies have dealt with the combined effect of the operating temperature and moisture content on the $\mathrm{k}$-values of the insulation materials. However, heat and mass conservation equations in porous media are coupled and, in general, solved iteratively by using the value of temperature and moisture content from previous iteration to calculate the source terms [24].

In this study the change of the operating temperature first and then the moisture content effects on the $\mathrm{k}$-values of EPS insulation material, which allow accurate calculation of the k-value of the insulation has been investigated. The results of this paper allow building engineers to assess accurately the thermal performance of building envelopes under real climatic condition based on more realistic data of building insulation materials.

\section{Measurement of Thermal Conductivity of Samples}

Prior to developing the experimental procedure for measuring the thermal conductivity of the samples at different operating temperatures, an experimental apparatus based on the transient plate source was designed (Fig. 1). The apparatus was subsequently calibrated using the known thermal conductivity values at $10{ }^{\circ} \mathrm{C}$ of three polystyrene insulation samples characterized by high, ultra-high, and super-high density (denoted as HD, UHD, and SHD, respectively) provided by another company [1].

A water reservoir shown in Fig. 2 was used in combination with a chiller and a heater-embedded water circulator pump. The description of the experimental procedure is detailed by several previous papers; see $[1,25]$. To ensure accuracy, all samples were tested in triplicates over an extended period and the average values, along with the reference levels, are shown in Table 1.

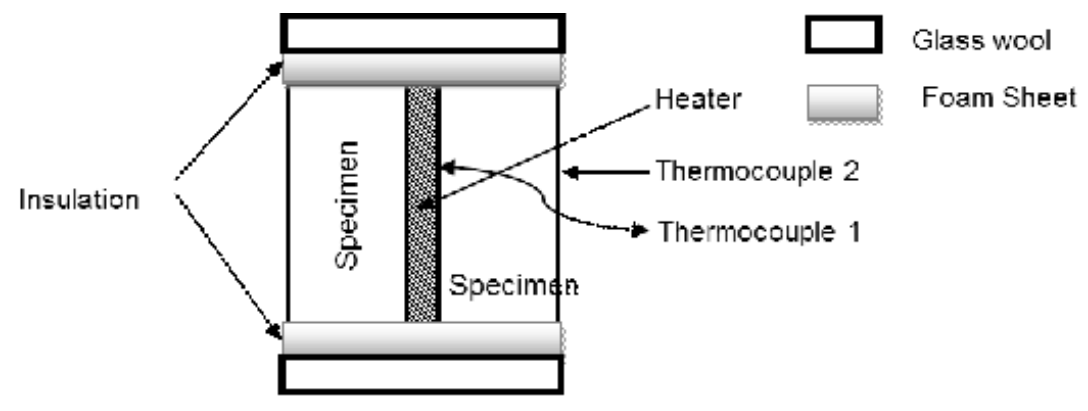

Fig. 1. Guarded hot plate 


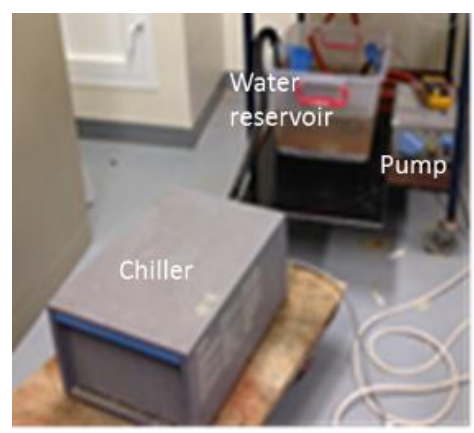

Fig. 2. Experimental setup, comprising of water reservoir, chiller, pump and heater.

The average measured thermal conductivities of the three samples and the reference values are within the acceptable range of accuracy. The difference pertaining to the UHD sample was the highest, at $4 \%$. Therefore, the designed apparatus was considered sufficiently accurate for use in the remaining measurements [4].

Table 1. Comparison between k-values of the three samples with the reference ones

\begin{tabular}{llll}
\hline Samples & $\begin{array}{l}\text { Average measured } \\
k \text {-value }\left(W m^{-1} K^{-1}\right)\end{array}$ & $\begin{array}{l}\text { k-value reference } \\
\left(W m^{-1} K^{-1}\right)\end{array}$ & $\begin{array}{l}\text { k-value difference } \\
(\%)\end{array}$ \\
\hline HD & 0.03588 & 0.035 & 2.5 \\
UHD & 0.03329 & 0.032 & 4 \\
SHD & 0.03046 & 0.03 & 1.5 \\
\hline
\end{tabular}

In order to moisturize the samples, an ultrasonic humidifier was utilized, as shown in Fig. 3, and a small acrylic chamber was designed to trap the moisture, and the sample was placed inside as illustrated by Fig. 4. The sample was elevated from the chamber floor via a metal mesh to prevent contact with the chamber surfaces, and thus ensure homogeneous moisture distribution around the sample (Fig. 5). More details are provided by [25].

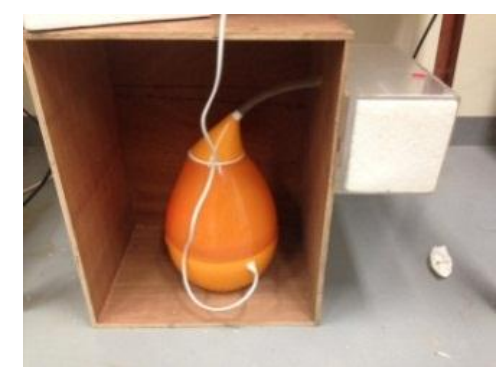

Fig. 3. Ultrasonic humidifier.

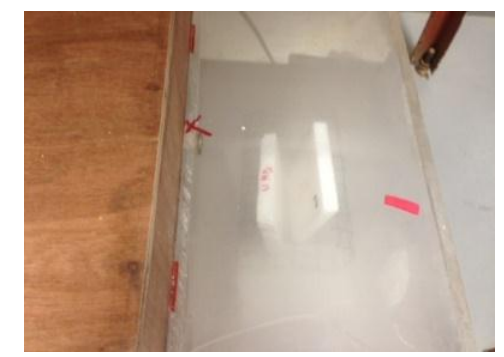

Fig. 4. Chamber filled with moisture. 


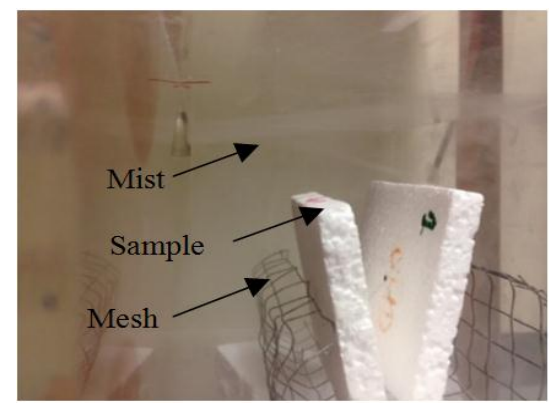

Fig. 5. Metal mesh carrying the samples

The impact of operating temperature on the thermal conductivity values of polystyrene insulation material with four density levels - low (LD), high (HD), ultra-high (UHD), and super-high (SHD) - is illustrated in Fig. 6. As can be seen from the graph, the thermal conductivity of all four samples is linear. While it is affected by the operating temperature to varying degrees, in all cases, higher temperature results in higher thermal conductivity. Moreover, thermal conductivity decreases with the increase in sample density.

The effect of the moisture content of the k-value of polystyrene insulation with different densities was investigated at 10,24 , and $28^{\circ} \mathrm{C}$ using the previously described apparatus. The findings revealed that the moisture content change at different operating temperatures had a very small effect on the k-value for the polystyrene insulation material designated as HD, UHD, and SHD. Indeed, they are impermeable to water and moisture transfer due to their high densities. Therefore, the investigation of the effect of the moisture content on the polystyrene insulation k-value was limited to the LD sample. The best-fit linear relationships between the $\mathrm{k}$-value and moisture content at a specified operating temperature are shown in Fig. 7. It should be noted that obtaining significant data at operating temperatures beyond $28{ }^{\circ} \mathrm{C}$ was a challenge due to the evaporation from the sample that took place during the measurement process.

In order to compare thermal conductivity variations for the different samples, the measured $\mathrm{k}$-values and the resulting operating temperature were established. This best-fit linear relationship is shown in Fig. 8. As can be seen from the graph, the thermal conductivity of the LD sample increases with the moisture content and operating temperature increase.

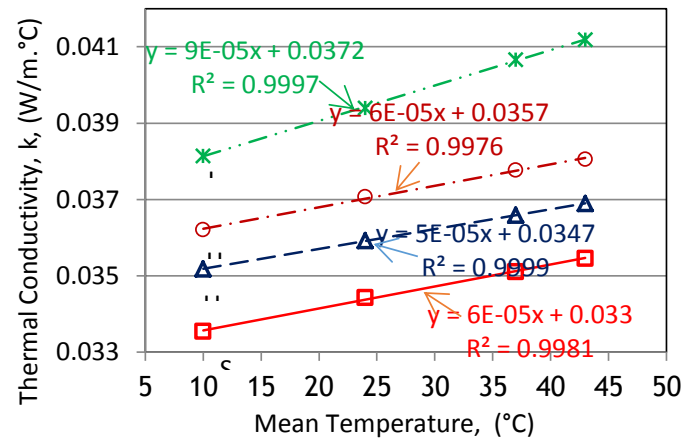

Fig. 6 Change of the k-value with different densities vs. temperatures.

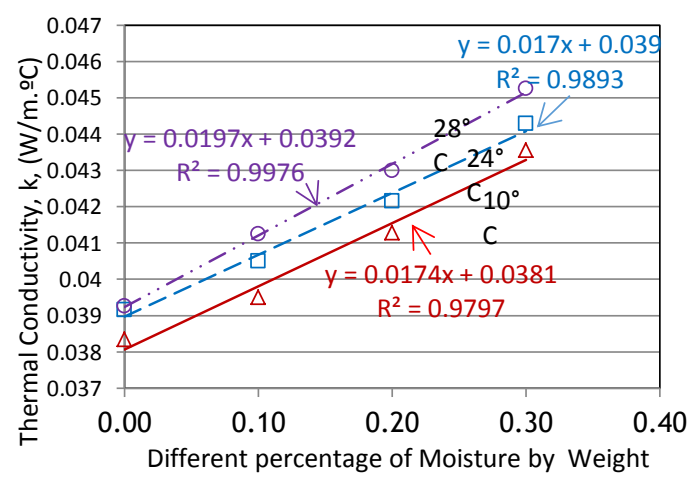

Fig. 7. Best fit change of k-values vs. moisture levels at 10,24 , and $28^{\circ} \mathrm{C}$. 


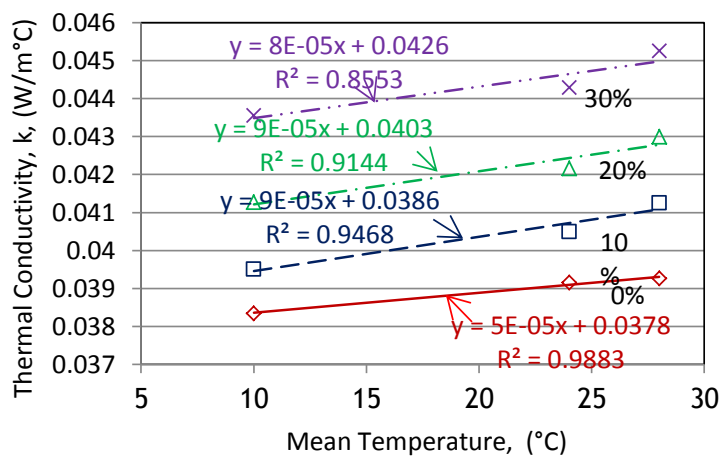

Fig. 8. Best-fit relationships of k-value measurement results of LD vs. operating temperatures and different percentages of moisture content by weight.

\section{Impact of Change of Thermal Conductivity on the Envelope -Induced Cooling Load}

Muscat is characterized by a hot-humid climate, with long and very hot summers and mild winters. The temperatures reaching as high as $49^{\circ} \mathrm{C}\left(120^{\circ} \mathrm{F}\right)$ in the summer. Annual rainfall in Muscat is about $100 \mathrm{~mm}$ ( $4 \mathrm{in})$ and is mostly restricted to the period between December and April. The average annual relative humidity is $57.6 \%$, whereby the average monthly relative humidity ranges from $42 \%$ in May to $67 \%$ in August. However, it can reach up to $90 \%$ in the coastal region.

For the purpose of the present investigation, a typical one-story building $(20 \times 10 \times 3 \mathrm{~m} 3)$ located in Muscat (Oman) was considered. The house was assumed to operate at a typical residential load profile with an average air-tightness of $0.5 \mathrm{ACH}$. Windows are tinted, double-glazed, and distributed uniformly over $2.5 \%$ of the wall area on the east, west, and south walls with $\mathrm{R}$-value $=3.34 \mathrm{~W} / \mathrm{m} 2{ }^{\circ} \mathrm{C}$ and overall shade coefficient $=0.811$.

The cooling load was computed using the Hourly Analysis Program (HAP) computer program utilizing the data of climate pertaining to Muscat assuming the house operating at a typical housing profile. HAP is a powerful tool designed for professionals involved in the design and analysis of commercial building HVAC systems. HAP uses the ASHRAE transfer function method for load calculations and detailed 8760 hour-per-hour simulation techniques for the energy analysis.

The variation in building cooling load due to the combined effect of temperature and moisture content is shown in Table 2. The wall/roof transmissions and the total zone loads increase with the increase in both the operating temperature and the moisture content. Indeed, the change is significant at high temperature and moisture content and is more pronounced for roof relative to the wall due to the important amount of solar radiation received on the roof surface. The extreme percentage change associated with the base case at $24^{\circ} \mathrm{C}$ and $0 \%$ moisture content is $7 \%, 13 \%$, and $7 \%$, respectively for the wall, roof, and the total zone loads at $28^{\circ} \mathrm{C}$ and $30 \%$ moisture.

Table 2. Change in the amount of cooling load due to the combined effect of temperature and moisture content

\begin{tabular}{clllllllll}
\hline & \multicolumn{3}{c}{ Cooling Load based on $\mathrm{k}_{10^{\circ} \mathrm{C}}(W)$} & \multicolumn{3}{l}{ Cooling Load based on $\mathrm{k}_{24^{\circ} \mathrm{C}}(W)$} & \multicolumn{4}{c}{ Cooling Load based on $\mathrm{k}_{28^{\circ} \mathrm{C}}(W)$} \\
\cline { 2 - 10 } & Wall & Roof & Zone & Wall & Roof & Zone & Wall & Roof & Zone \\
\hline $0 \%$ & 998 & 2909 & 6794 & 1003 & 2958 & 6848 & 1006 & 2964 & 6857 \\
\hline $10 \%$ & 1007 & 2979 & 6873 & 1020 & 3036 & 6943 & 1027 & 3080 & 6994 \\
\hline $20 \%$ & 1026 & 3081 & 6994 & 1037 & 3132 & 7055 & 1045 & 3180 & 7112 \\
\hline $30 \%$ & 1047 & 3211 & 7145 & 1056 & 3253 & 7196 & 1067 & 3306 & 7260 \\
\hline
\end{tabular}




\section{Variation of the K-value of the Insulation with Changes in Temperature within the Thickness of the Material}

The temperature to which the insulation materials are exposed depends on several parameters, including the thermal resistance of the material, the location of the insulation layer within the wall or roof assembly or system, and the effective or operating temperature (te) [1]. Te is a function of several parameters, including the outdoor air temperature, the surface solar absorbance of the system (wall or roof), the total solar radiation on the system surface, and the outdoor surface conductance [4]. The temperature at any location within the wall at steady-state conditions can be given by [8]

$$
t_{x}=t_{e}-R_{x} / R_{t o t}\left(t_{o}-t_{i}\right)
$$

where $t_{\mathrm{e}}=$ effective outdoor temperature; $\mathrm{R}_{\mathrm{x}}=$ portion of thermal resistance measured from within; $\mathrm{R}_{\text {tot }}=$ total thermal resistance of the envelope assembly; $t_{0}=$ outdoor air temperature; and $t_{i}=$ indoor air temperature [1]. The effective outdoor temperature, also known as sol-air temperature is given by [8]

$$
t_{e}=t_{o}+\alpha I_{t} / h_{o}-\varepsilon \Delta R / h_{o}
$$

where $\alpha=$ surface solar absorbance; $\mathrm{I}_{\mathrm{t}}=$ total solar radiation; $\mathrm{h}_{\mathrm{o}}=$ outdoor surface conductance; and $\varepsilon \Delta \mathrm{R} / \mathrm{h}_{\mathrm{o}}=$ correction factor (equal to zero for vertical surface).

The total solar radiation is given by

$$
I_{t}=H_{b}\left(\frac{\cos \theta}{\cos \theta_{z}}\right)+H_{d}\left(\frac{1+\cos \theta}{2}\right)+\rho_{g r} H\left(\frac{1-\cos \beta}{2}\right)
$$

where $\mathrm{H}_{\mathrm{b}}=$ direct horizontal radiation; $\mathrm{H}_{\mathrm{d}}=$ diffuse horizontal radiation; $\mathrm{H}=$ global horizontal radiation; $\rho_{\mathrm{gr}}=$ ground albedo; $\theta=$ incident angle; and $\beta=$ slope $\left(90^{\circ}\right.$ for vertical wall and $0^{\circ}$ for horizontal roof). A

\begin{tabular}{|c|c|c|}
\hline & Wall & Roof \\
\hline & $\begin{array}{c}13 \mathrm{~mm} \text { interior gypsum } \\
200 \mathrm{~mm} \text { concrete block } \\
50 \mathrm{~mm} \text { insulation } \\
19 \mathrm{~mm} \text { concrete stucco (from the } \\
\text { exterior) }\end{array}$ & $\begin{array}{c}15 \mathrm{~mm} \text { plaster (from the interior) } \\
200 \mathrm{~mm} \text { concrete slab } \\
\text { Water proof membrane } \\
50 \mathrm{~mm} \text { concrete } \\
75 \mathrm{~mm} \text { polystyrene insulation } \\
\text { Weather resistant barrier } \\
30 \mathrm{~mm} \text { sandstone }\end{array}$ \\
\hline $\mathrm{R}$-value & $2,79\left(m^{2} C / W\right)$ & $2,4\left(m^{2} C / W\right)$ \\
\hline
\end{tabular}
commonly used wall and roof construction is modeled. The details of the construction is given in Table 3 .

Table 3. Details of the wall and roof construction

Figs 9-12 show the change in insulation polystyrene thermal conductivity as a function of temperature at the mid-thickness of the material for different percentages of moisture content for horizontal and vertical surfaces during the daytime with dark and light color of the external surfaces. These curves have been plotted with the reference k-value of polystyrene insulation obtained at $24^{\circ} \mathrm{C}$. It is evident from the graphs that the k-value of the samples increases with the increase of the moisture content within the layer of the samples and the operating temperatures. Moreover, the change of the k-value of the roof is more significant compared to the wall, due to the huge amount of the solar radiation received on the horizontal surface, which is also higher for dark color compared with a light one. 


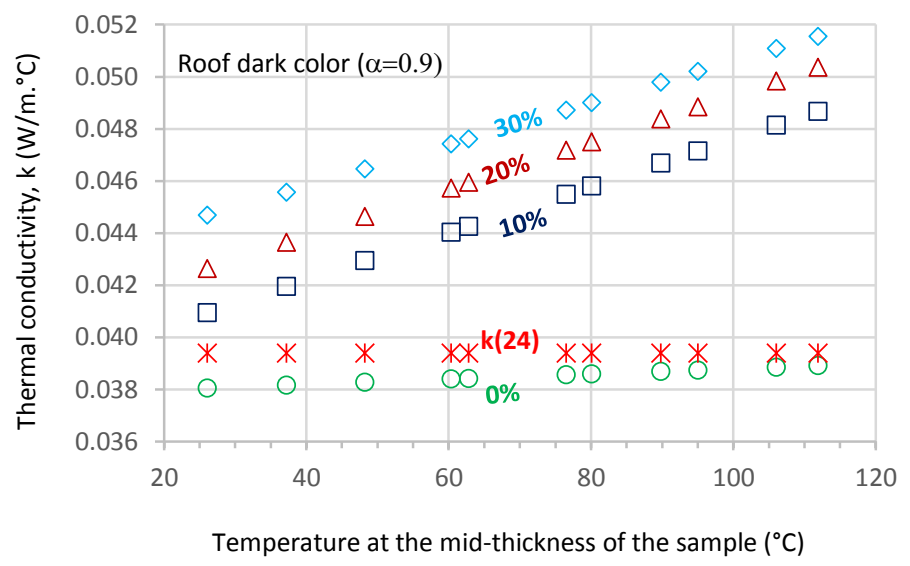

Fig. 9. Change in polystyrene k-value as a function of temperature at the mid-thickness of the material for different percentage of moisture content and k-reference comprising a horizontal surface (roof) during daytime with roof dark color $(\alpha=0.9)$.

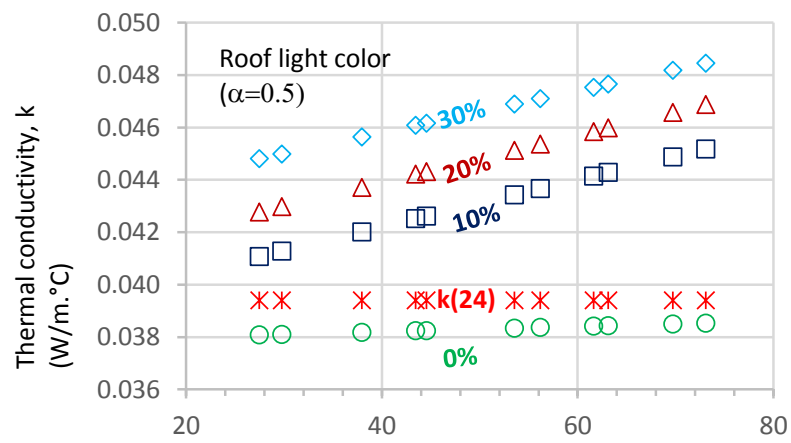

Temperature at the mid-thickness of the sample $\left({ }^{\circ} \mathrm{C}\right)$

Fig. 10. Change in polystyrene k-value as a function of temperature at the mid-thickness of the material for different percentage of moisture content and k-reference comprising a horizontal surface (roof) during daytime with roof light $\operatorname{color}(\alpha=0.5)$.

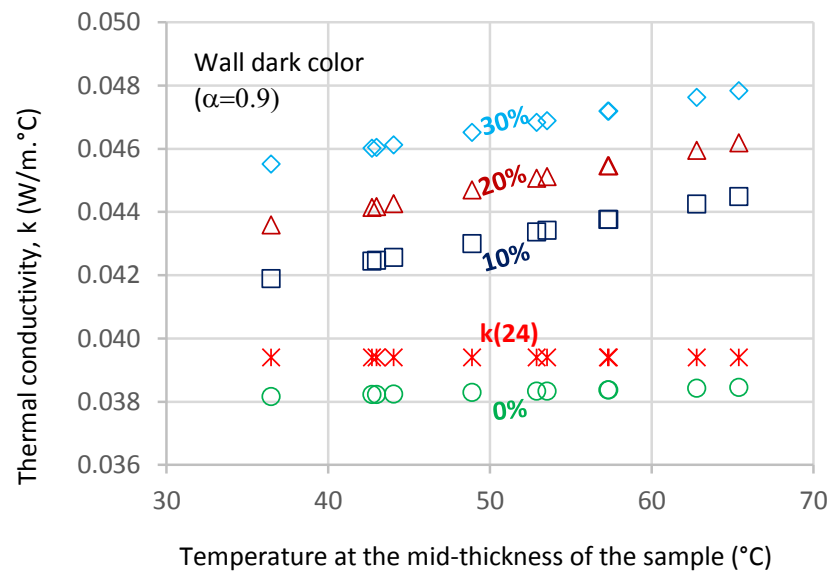

Fig. 11. Change in polystyrene k-value as a function of temperature at the mid-thickness of the material for different percentages of moisture content and k-reference comprising a vertical surface (wall) during daytime with roof dark color $(\alpha=0.9)$. 


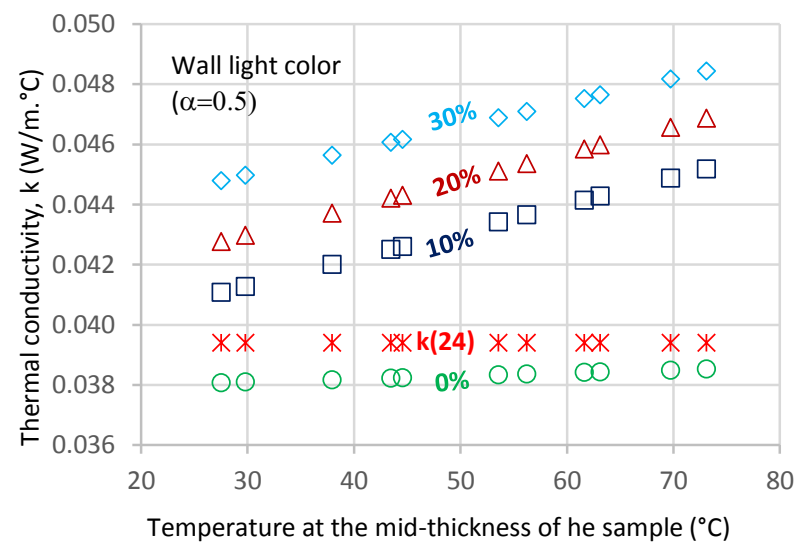

Fig. 12. Change in polystyrene k-value as a function of temperature at the mid-thickness of the material for different percentages of moisture content and k-reference comprising a vertical surface (wall) during daytime with roof light color $(\alpha=0.5)$.

\section{Conclusion}

The combined impact of temperature and humidity content on the change in the thermal conductivity of building polystyrene material and its impact on the energy performance of building was investigated in this work. The findings revealed that the impact of this change on the cooling load calculation is significant, especially at a high operating temperature and moisture content. This effect is also more pronounced for the roof compared to the wall. These results indicate that, in hot-humid climate, the change of the $\mathrm{k}$-value of the insulation should be taken into account to increase building energy performance assessment accuracy.

Increasing the operating temperature and the moisture content, the k-value of the LD increases. Moreover, the change of the k-value for the roof is more significant compared to the wall, due to the huge amount of the solar radiation that falls on a horizontal surface, which is also higher for the dark color compared with a light one.

The results of this study confirm the necessity to require from the building insulation material manufactures to provide, at various operating temperatures and humidity contents for different densities, the thermal conductivity of their products, to allow accurate building energy assessment by building designers. This study should be also extended to other insulation materials, including fiberglass, mineral wool, cellulose, and polyurethane foam which could also be sensitive to the variation of the combined effect of temperature and humidity.

\section{References}

[1] Khoukhi M, Fezzioui N, Draoui B, Salah L. The impact of changes in thermal conductivity of polystyrene insulation material under different operating temperatures on the heat transfer through the building envelope. Applied Thermal Engineering, 2016; 105: 669-674.

[2] ASTM Standard C 168-97. Terminology relating to thermal insulating materials, 1997.

[3] Khoukhi M. The combined effect of heat and moisture transfer dependent thermal conductivity of polystyrene insulation material: impact on building energy performance. Energy and Buildings, 2016; 169: 228-674.

[4] ASTM 518, Standard Test Method for Steady-Stathe Thermal Transmission Properties by Means of the Heat Flow Meter Apparatus, 2015.

[5] ISO 8301, Thermal insulation-Determination of steady-state thermal resistance and related properties - Heat flow meter apparatus, 1991.

[6] Budaiwi I, Abdou A. Effect of thermal conductivity change of moist fibrous insulation on energy performance of buildings under hot-humid conditions. Energy and Buildings, 2013; 60: 388-399.

[7] Kontoleon KJ, Giarma C. Dynamic thermal response of building material layers in aspect of their moisture content. Applied Energy; 2016; 170:76-91. 
[8] Budaiwi I, Abdou I, Al-Homoud M. Variation of thermal conductivity of insulation Materials under different operating temperatures: Impact on envelope-induced cooling load. Journal of Architectural Engineering, 2002; 8:125-132.

[9] Aldrich DF, Bond RH. Thermal performance of rigid cellular foam insulation at subfreezing temperature thermal performance of exterior envelopes of buildings III. ASHRAE/DOE/BTECC Conference, Florida, December 2-5, pp. 500, 1985.

[10] Wilkes KE and Child PW. Thermal performance of fiberglass and cellulose attic insulation. thermal performance of exterior envelopes of buildings V. ASHRAE/DOE/BTECC/CIBSE Conference, Clear Water Beach, Florida, 1992 December 7-10; 357.

[11] Al-Hammad A, Abdelrahman MA, Grondzik W, Hawari A. A comparison between actual and published k-values for Saudi insulation materials. Journal of Thermal Insulation and Building Envelope, 1994; 17:378-385.

[12] Khoukhi M, Tahat M. Effect of operating temperatures on thermal conductivity of polystyrene insulation material: impact on envelope-induced cooling load. Applied Mechanic of Materials, 2014; 564:315-320.

[13] Khoukhi M, Tahat M. Effect of temperature and density variation on thermal conductivity of polystyrene insulation materials in Oman. Journal of Engineering Physics and Thermophysics, 2015; 88:994-998.

[14] Abdou A, Budaiwi I. Comparison of thermal conductivity measurements of building insulation materials under various operating temperature. Journal of Building Physics, 2005; 29:171-184.

[15] Berardi U, Naldi M. The impact of the temperature dependent thermal conductivity of insulating materials on the effective building envelope performance. Energy and Buildings, 2017; 144:262-275.

[16] Ochs F, Heidemann W, Müller-Steinhagen H. Effective thermal conductivity of moistened insulation materials as a function of temperature International Journal of Heat and Mass Transfer, 2008; 51 (3-4):539-552.

[17] Jerman M, Cerny R. Effect of moisture content on heat and moisture transport and storage properties of thermal insulation materials. Energy and Buildings, 2012; 53:39-46.

[18] Jina HQ, Yaoa XL, Fana, LW, Xu X, Yua Zi ZT. Experimental determination and fractal modeling of the effective thermal conductivity of autoclaved aerated concrete: effects of moisture content. International Journal of Heat and Mass Transfer, 2016; 92:589-602.

[19] Pérez BJM, Dominguez HJ, Cano SE, Del Coz Díaz JJ, Álvarez Rabanal FP. A correction factor to approximate the design thermal conductivity of building materials. Application to Spanish façades. Energy and Buildings, 2015; 88:153-164.

[20] Pérez BJM, Dominguez HJ, Cano SE, Alonso MM, del Coz Díaz JJ. Detailed territorial estimation of design thermal conductivity for façade materials in North-Eastern Spain. Energy and Buildings, 2015; 102:266-276.

[21] Clarke JA, Yaneske PP. A rational approach to the harmonization of the thermal properties of building materials. Building and Environment; 2009; 44:2046-2055.

[22] Menyhart K, Krarti M. Potential energy savings from deployment of Dynamic Insulation Materials for US residential buildings. Building and Environment, 2017; 114:203-218.

[23] Jelle BP. Traditional, state-of-the-art and future thermal building insulation materials and solutions - properties, requirements and possibilities. Energy and Buildings, 2011; 43:2549-2563.

[24] Mendes N, Philippi PC, Lamberts R. A new mathematical method to solve highly coupled equations of heat and mass transfer in porous media. International Journal of Heat and Mass Transfer, 2002; 45:509-518.

[25] Khoukhi M. Thermal performance of common building insulation materials: Operating temperature and moisture effect. Presented at the 19th International Conference on Civil Engineering and Architecture, Montreal Canada, May 11-12, 2017. 